\title{
Parâmetros pedológicos para estimativa de vazões em bacias hidrográficas
}

\section{Pedological parameters for flow simulation in river basins}

\author{
Luana Lavagnoli Moreira ${ }^{1 *}$, Dimaghi Schwamback ${ }^{2}$, Daniel Rigo ${ }^{3}$ \\ ${ }^{1}$ Doutoranda em Recursos Hídricos e Saneamento Ambiental, Universidade Federal do Rio Grande do Sul, Porto Alegre; lavagnoliluana@gmail.com; \\ ${ }^{2}$ Mestrando em Engenharia Hidráulica e Saneamento, Universidade de São Paulo, dimaghi@usp.br; ${ }^{3}$ Professor Doutor do Programa de Pós-graduação em \\ Engenharia Ambiental, Universidade Federal do Espírito Santo, rigo@npd.ufes.br
}

\section{A R T I G O}

Recebido: 02/08/2018

Aprovado: 11/11/2018

Palavras-chave:

Modelo hidrológico

Parâmetros de pedologia

SWAT.

Key words:

Hydrological model

Soil database

SWAT.

\begin{abstract}
R E S U M O
Modelos hidrológicos, como o Soil and Water Assessment Tools (SWAT), são poderosas ferramentas para o gerenciamento de recursos hídricos. Entretanto, seu uso depende de muitos dados de entrada, comumente oriundos de bases internacionais e nacionais não realísticas. Dentre os dados de entrada, informações pedológicas em níveis regionais e locais são tidas como as mais críticas de obtenção e manuseio, especialmente em regiões em desenvolvimento como o Brasil, e a carência dessas informações leva a incertezas em simulações. O presente artigo tem como objetivo apresentar os procedimentos necessários para a obtenção dos valores de cada parâmetro pedológico exigido pelo modelo SWAT para estimativa de vazões em bacias hidrográficas. Ao longo trabalho são elencados os procedimentos para obtenção dos parâmetros pedológicos para cada classe de solo e ao seguir tal metodologia, foram identificados os valores para as classes presentes na área de estudo. O estudo se aplica à bacia do rio Jucu, localizada no estado do Espírito Santo, sendo referência e base de dados a futuros estudos hidrológicos da mesma região ou de outras; em vez de usar valores pouco coerentes com a realidade local.
\end{abstract}

\section{A B S T R A C T}

\begin{abstract}
Hydrological models, such as Soil and Water Assessment Tools (SWAT), are powerful water resources management tool. However, its use depends on many input data, generally from international/national bases that do not represent the regional reality of a local study. Among the input data, pedological information at regional and local scale is considered the most critical to obtaining and handling, especially in developing regions such as Brazil, and its lack leads to uncertainties in its simulations. The present paper has the purpose of present required procedures in order to obtain the values of each pedological parameter required by the SWAT to estimate average flows in watersheds. Throughout this paper are listed the procedures to obtain the pedological parameters for each class of soil, and by following these steps, we identified the values for the classes present in the study area. The study is applied to the Jucu river basin, located in the state of Espírito Santo, and will serve as reference and database for further hydrological studies of the same region or others, instead of using values that are inconsistent with their locality.
\end{abstract}

\section{INTRODUÇÃO}

A gestão integrada e a alocação adequada dos recursos hídricos aos usuários da água são importantes desafios já enfrentados pela sociedade ou que necessitarão de maior atenção nas próximas décadas (COSGROVE; LOUCKS, 2015; SIMONOVIC, 2002).

Desde a segunda metade do século XX, uma variedade de modelos hidrológicos tem sido desenvolvida, com destaque para o Soil and Water Assessment Tool - SWAT (ARNOLD et al., 1998). Sua repercussão mundial no meio científico atribui-se à sua elevada acurácia e precisão em simular a quantidade e a qualidade da água, em nível de bacia hidrográfica, sob diferentes usos e manejos do solo ao longo do tempo, sendo capaz de representar situações passadas, presentes e futuras (ABBASPOUR, 2015; FRANCESCONI et al., 2016; LEYTON, 2012; OCHOA; URBINACARDONA, 2017).

O SWAT pode ser classificado como um modelo de simulação matemática contínuo, semidistribuído, determinístico e semiconceitual (ARNOLD et al., 2012). Requer informações (dados de entrada) locais de clima, solo, nutrientes, uso e conservação do solo e hidrologia.

Dentre os parâmetros necessários, dados pedológicos são fundamentais em análises hidrológicas de avaliação de práticas de conservação e poluição ambiental por refletirem 
fenômenos tais como a evapotranspiração, a fotossíntese e os ciclos biogeoquímicos (DI LUZIO, 2015). Apesar de sua importância, constituem-se como os mais desafiadores para obtenção de toda a base de dados a ser levantada, além de sua extrema complexidade de inserção e manuseio (LEYTON, 2012).

Nos Estados Unidos, país onde o SWAT foi desenvolvido, dados nacionais de pedologia e uso do solo estão disponíveis para seu pronto download e uso (LEYTON, 2012). Entretanto, em regiões em desenvolvimento, como África e América do Sul, a disponibilidade dessas informações é escassa, incompleta ou inexistente e de baixa qualidade ou incerta (BRESSIANI et al., 2015; STEHR et al., 2008). Tais limitações levam muitos pesquisadores adotarem a base de dados norteamericana, apesar de o solo brasileiro diferir por suas particularidades tropicais, como pela alta espessura de camadas, baixa troca de cátions e elevada permeabilidade, resultando em erros nas equações presentes no modelo SWAT correspondentes a desprendimento de solo e infiltração (BUOL, 2009; LEPSCH, 2013).

A principal razão pela escassez de dados de solo é que métodos convencionais de amostragem requerem grande quantidade de mão de obra, tempo e recursos (AKSOY et al., 2009), por isso o desenvolvimento de metodologias que possam preencher as lacunas existentes é importante (LEYTON, 2012).

Diferentes procedimentos podem ser utilizados com o objetivo de suprir a inexistência de dados pedológicos locais. Magaló et al. (2017), Kouchi et al. (2017), Gyamfi et al. (2016) e Eman (2016) utilizaram dados de pedológicos provenientes de um banco de dados mundial compilado pela Organização das Nações Unidas para a Alimentação e a Agricultura (FAO). Brouziyne et al. (2017) identificaram as variáveis físicas e químicas necessárias por meio de um levantamento de campo, enquanto que a condutividade hidráulica e a capacidade de campo foram determinadas empiricamente por da equação de Saxton. Embora Fukunaga et al. (2015) tenham utilizado dados nacionais (levantamento semidetalhado de solos do Projeto Jequitaí, Minas Gerais), estes não se configuram como locais, considerando as dimensões continentais do Brasil.

Ainda que não tenha sido o foco das pesquisas citadas anteriormente, Tarawneh et al. (2016) ressaltam que a acurácia dos resultados da modelagem pode ser melhorada por meio do uso de dados de entrada regionais. Com base na lacuna evidenciada, esta pesquisa tem por objetivo, a partir do uso de diferentes procedimentos, obter dados pedológicos para as classes pedológicas existentes na bacia hidrográfica do rio Jucu, sul do estado do Espírito Santo, Brasil.

\section{MATERIAL E MÉTODOS}

O estudo da estimativa de parâmetros pedológicos para modelagem hidrológica faz aplicação à bacia hidrográfica do rio Jucu, localizada no sul do estado do Espírito Santo, Brasil, abrangendo uma área de $2.014 \mathrm{~km}^{2}$, cuja extensão de cursos d'água é de aproximadamente $5.130 \mathrm{~km}$ e a densidade de drenagem é $2,54 \mathrm{~km} / \mathrm{km}^{2}$. A localização da região de estudo é apresentada na Figura 1.

A bacia do rio Jucu é formada pelos municípios de Domingos Martins, Marechal Floriano, Viana, Vila Velha, Cariacica e Guarapari. Limita-se com a baía de Vitória a Leste, com a bacia hidrográfica do Rio Santa Maria da Vitória e Doce ao Norte e a Oeste, com a bacia hidrográfica do rio Itapemirim a Sudoeste e com a bacia hidrográfica do rio Benevente ao Sul. Entre os cursos d'água que compõem a bacia em estudo, citam-se os rios Jucu Braço Norte, Jucu Braço Sul, Formate, Marinho, Jacarandá, Clarinho, Claro, das Pedras, Galo, Melgaço, Ponte, Barcelona, ribeirão D'Anta, dentre outros.

Figura 1. Localização da bacia hidrográfica do rio Jucu, estado do Espírito Santo, Brasil

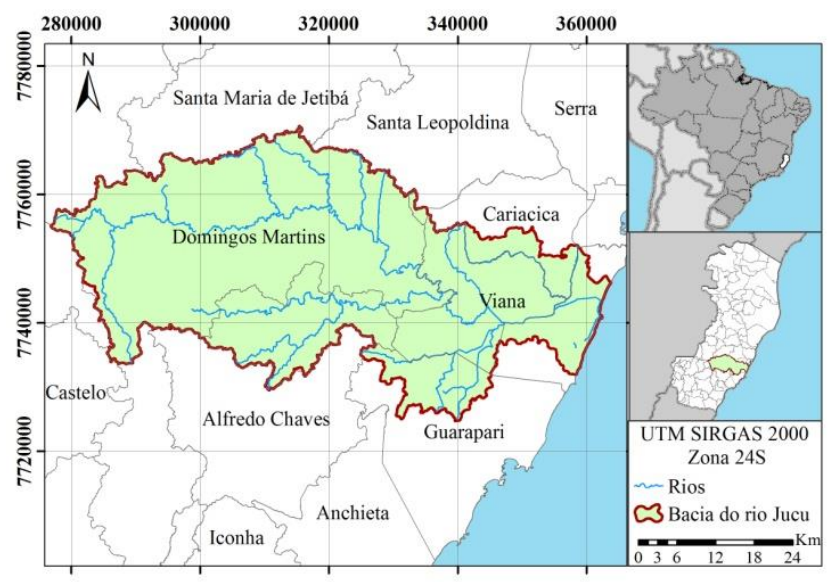

Fonte: Elaborada pelo autor (2018)

As estimativas de vazões pelo modelo SWAT dependem de dados de entrada correlacionados às características físiográficas (altitude, uso e ocupação do solo e pedologia) e climáticas (radiação solar, temperatura do ar, precipitação pluviométrica, umidade relativa do ar e velocidade do vento) da bacia hidrográfica em foco. Todas esses componentes são integrados ao SWAT por meio de um Sistema de Informação Geográfica (SIG), ArcSWAT, conforme metodologia apresentada por Moreira et al. (2018).

Quanto à variável pedológica, foi necessária a apresentação de uma série de parâmetros acoplados ao modelo SWAT, os quais variaram de acordo com as características da região de estudo. Segundo Arnold et al. (2012), a definição de cada parâmetro relacionado às estimativas de vazões é descrita como: NLAYERS - número de horizontes do solo; SOL_Z - Profundidade de cada horizonte (mm); HYDGRP - Grupo hidrológico do solo (A, B, C ou D); SOL_AWC - Quantidade de água disponível para as plantas (mm_H ${ }_{2} \mathrm{O} / \mathrm{mm} \_$Solo); SOL_K - Condutividade hidráulica do solo $(\mathrm{mm} / \mathrm{h})$; SOL_BD - Densidade do solo $\left(\mathrm{g} / \mathrm{cm}^{3}\right)$; CLAY - Porcentagem de argila no solo (\%); SAND Porcentagem de areia no solo (\%); SILT - Porcentagem de silte no solo (\%); ROCK - Porcentagem de cascalho no solo (\%).

O banco de dados do SWAT apresenta valores de parâmetros de acordo com as características pedológicas da América do Norte, região na qual o modelo foi desenvolvido. Para sua aplicação e obtenção de resultados acurados, foi necessário incluir nesse banco de dados os tipos de solo da bacia hidrográfica em estudo, acompanhados de suas características pedológicas.

As informações pedológicas da bacia hidrográfica do rio Jucu foi provenientes do levantamento realizado em todo o estado do Espírito Santo pela Empresa Brasileira de Pesquisa Agropecuária (Embrapa) em 1978 em uma de escala espacial de 1:400.000. 
Os valores para cada parâmetro, conforme cada horizonte do solo, foram obtidos por meio das amostragens realizadas pela Empresa Brasileira de Pesquisa Agropecuária - Embrapa - durante o levantamento de reconhecimento de solos no estado do Espírito Santo em 1978 e pela classificação de grupos hidrológicos de Sartoni et al. (2005). O levantamento consistiu em identificar os diferentes tipos de solo do estado citado, além de indicar a distribuição geográfica e caracterizar os aspectos morfológicos, físicos, químicos e mineralógicos das diferentes classes pedológicas por meio de amostras obtidas em campo. Os valores dos parâmetros foram obtidos a partir dos dados dessas amostras de solo coletadas na bacia estudada neste trabalho.

O parâmetro HYDGRP (grupo hidrológico), relacionado às características de infiltração do solo, foi obtido através da seguinte classificação citada por Sartoni et al. (2005): Grupo A - Latossolo amarelo, latossolo vermelho amarelo, latossolo vermelho, de textura argilosa ou muito argilosa e com alta macroporosidade; latossolo amarelo e latossolo vermelho amarelo, ambos de textura média, mas com horizonte superficial não arenoso; Grupo B - Latossolo amarelo e latossolo vermelho amarelo, ambos de textura média, mas com horizonte superficial de textura arenosa; latossolo bruno, nitossolo vermelho, neossolo quartzênico e argilossolo vermelho ou vermelho amarelo de textura arenosa/média, média/argilosa, argilosa/argilosa, argilosa/muito argilosa, os quais não apresentam mudança textural abrupta; Grupo C Argissolos pouco profundos, mas não apresentando mudança textural abrupta; argissolo vermelho, argiloso; argissolo vermelho amarelo e argissolo amarelo, ambos profundos e apresentando mudança textural; cambissolo de textura média e cambissolo háplico ou húmico, mas com características físicas semelhantes aos latossolos, espodossolo ferrocárbico e neossolo flúvico; Grupo D - Neossolo litólico; organossolo; gleissolo; chernossolo; planossolo; vertissolo; alissolo; luvissolo; plintossolo; solos de mangue; afloramentos de rocha; demais cambissolos que não se enquadram no grupo C; argissolo vermelho amarelo e argissolo amarelo, ambos pouco profundos e associados à mudança textural abrupta.

$\mathrm{O}$ parâmetro SOL_AWC (quantidade de água disponível) foi obtido, de acordo com cada horizonte do solo, através dos valores de umidade equivalente para cada tipo do solo, segundo os dados fornecidos pela Embrapa (1978). De acordo com Dias Junior et al. (2000), a umidade equivalente (UE) do solo corresponde à umidade que uma amostra de solo retém quando, depois de saturada, é submetida à centrifugação por 30 minutos com velocidade 1000 vezes maior que a gravidade. Por meio da umidade equivalente, pode-se estimar a capacidade de campo (FC) e a fração de água no ponto de murcha permanente (WP) pelas equações (01) e (02).

$$
\begin{aligned}
W P & =0,68 * U E \\
F C & =1,3 * U E
\end{aligned}
$$

A quantidade de água disponível para as plantas (SOL_AWC) é a subtração do valor da capacidade de campo (FC) em relação ao valor da fração de água no ponto de murcha permanente (WP). Dessa forma, o parâmetro SOL_AWC foi estimado pela expressão (03).

$$
S O L \_A W C=1,3 * U E-0,68 * U E
$$

Os parâmetros indicando o número de horizontes do solo (NLAYERS), a profundidade do solo (SOL_Z), a densidade do solo (SOL_BD) e as concentrações de argila (CLAY), areia (SAND), silte (SILT) e cascalho (ROCK) foram obtidos diretamente através dos valores presentes nos resultados das amostras do estudo da Embrapa (1978), conforme cada horizonte do solo.

Quanto ao parâmetro de condutividade hidráulica (SOL_K), ele foi estimado, para cada horizonte do solo, com base na textura do solo obtida através do triângulo textural desenvolvido pelo Serviço de Conservação do Solo do Departamento de Agricultura dos Estados Unidos (SCS, 1987), como apresentado na Figura 2.

Figura 2. Triângulo textural do solo

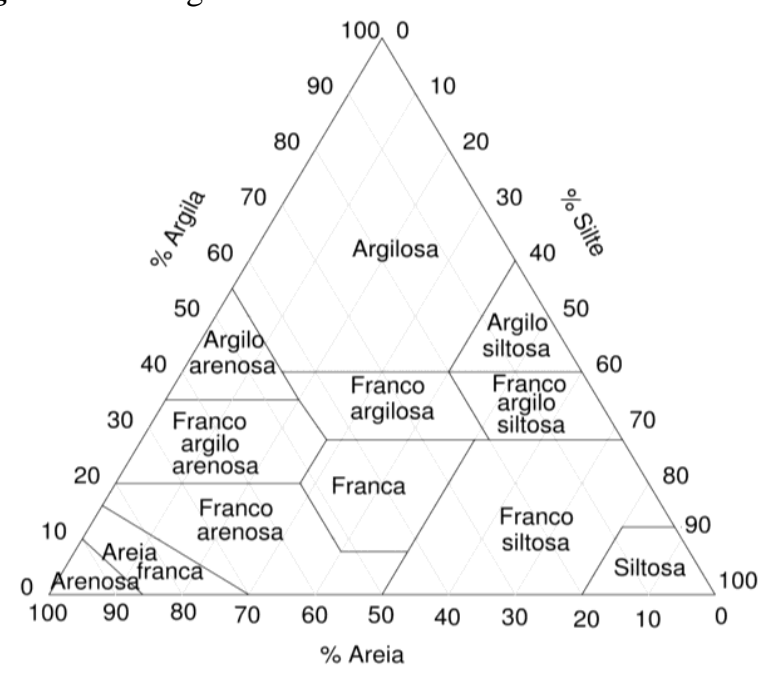

Fonte: Adaptado de SCS, 1987

As extremidades do triângulo textural apresentam 100\% de concentração de areia, argila ou silte. É importante citar que as porcentagens de cascalho e material orgânico não fazem parte da análise. O triângulo é dividido em porções de $10 \%$ de argila, silte e areia, enquanto as linhas espessas mostram a divisão entre 12 classes texturais de solos. Uma vez que as porcentagens de areia, argila e silte são conhecidas para cada tipo de solo, é possível determinar a classe textural (SCS, 1987).

A correlação entre a textura do solo e a condutividade hidráulica é realizada a partir de dados de literatura científica provenientes da pesquisa de Dent e Young (1981), como apresentado na Tabela 1 .

Tabela 1. Classificação textural e condutividade hidráulica

\begin{tabular}{lc}
\hline \multicolumn{1}{c}{ Textura } & $\begin{array}{c}\text { Condutividade } \\
\text { hidráulica }(\mathrm{mm} / \mathrm{h})\end{array}$ \\
\hline Arenosa & $250-500$ \\
Areia franca & $120-250$ \\
Franco-arenosa & $60-120$ \\
Franco-argilosa, silte, franco-siltosa, franca & $20-60$ \\
Argila, argilo-siltosa, argilo-arenosa, franco- & $5-20$ \\
argilo-siltosa, franco-argilosa, franco-siltosa, & \\
silte, franco-argilo-arenosa & \\
Argila, franco-argilosa, argilo-siltosa, franco- & $2,5-5$ \\
argilo-arenosa & $<2,5$ \\
Argila & \\
\hline
\end{tabular}

Fonte: Adaptado de Dent e Young (1981)

\section{RESULTADOS E DISCUSSÃO}

Os solos pertencentes à região de estudo e sua respectiva porcentagem de área na bacia hidrográfica são apresentados na Tabela 2 e ilustrados na Figura 3. 
Tabela 2. Pedologia da bacia do rio Jucu, estado do Espírito Santo, Brasil

\begin{tabular}{lcc}
\hline \multicolumn{1}{c}{ Nome do solo } & Sigla & $\begin{array}{c}\text { Porcentagem } \\
\text { de área }\end{array}$ \\
\hline $\begin{array}{l}\text { Latossolo vermelho amarelo distrófico A } \\
\text { moderado, textura argilosa fase floresta } \\
\text { subperenifólia, relevo forte ondulado }\end{array}$ & LVd2 & $6,10 \%$ \\
$\begin{array}{l}\text { Latossolo vermelho amarelo distrófico A } \\
\text { moderado, textura argilosa fase floresta } \\
\text { subperenifólia, relevo montanhoso e forte } \\
\text { ondulado }\end{array}$ & LVd3 & $67,53 \%$ \\
$\begin{array}{l}\text { Latossolo vermelho amarelo distrófico A } \\
\text { moderado, textura argilosa fase floresta } \\
\text { subperenifólia, relevo suave ondulado }\end{array}$ & LVd12 & $1,87 \%$ \\
$\begin{array}{l}\text { Cambissolo háplico distrófico A } \\
\text { moderado, textura argilosa e média fase } \\
\text { floresta perenifólia, relevo montanhoso e } \\
\text { forte ondulado }\end{array}$ & Cd1 & $14,74 \%$ \\
$\begin{array}{l}\text { Argissolo vermelho amarelo álico A } \\
\text { moderado, textura argilosa fase floresta } \\
\text { subcaducifólia, relevo ondulado }\end{array}$ & PV2 & $0,89 \%$ \\
$\begin{array}{l}\text { Neossolo quartzarênico distrófico A } \\
\text { moderado, fase arenosa floresta } \\
\text { subperenifólia de restinga, relevo plano }\end{array}$ & AMd2 & $3,07 \%$ \\
$\begin{array}{l}\text { Neossolo flúvico distrófico A fraco e } \\
\text { moderado, textura média fase floresta } \\
\text { perenifólia de vársea, relevo plano }\end{array}$ & Ad1 & $4,07 \%$ \\
$\begin{array}{l}\text { Neossolo litólico eutrófico A moderado, } \\
\text { textura média e argilosa floresta } \\
\text { subperenifólia e subcaducidólia, relevo } \\
\text { escarpado, montanhoso e forte ondulado }\end{array}$ & & \\
\hline
\end{tabular}

Figura 3. Classes pedológicas da bacia do rio Jucu, estado do Espírito Santo, Brasil

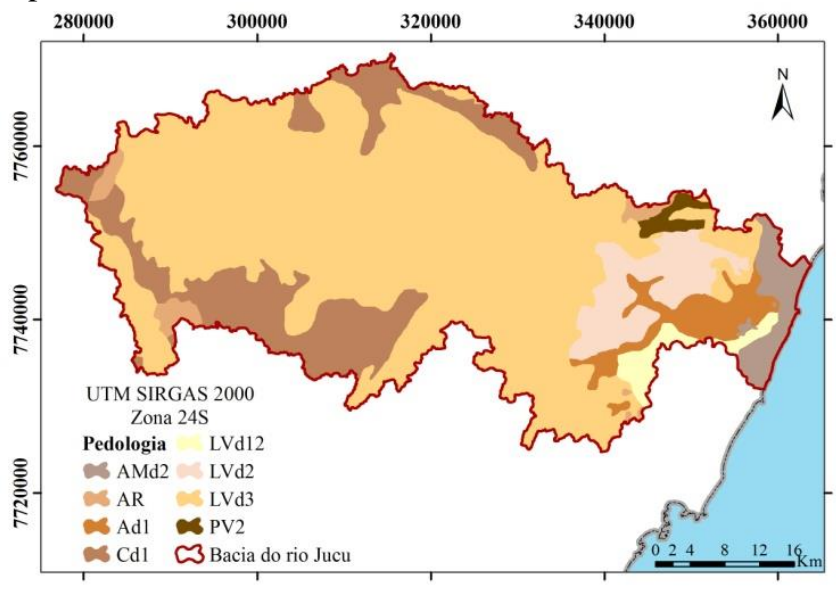

Fonte: Elaborada pelo autor (2018)

A maior parte da bacia do rio Jucu (mais de 75\%) apresenta a classe pedológica Latossolo vermelho amarelo, ocupando a porção média e alta da bacia, como pode ser observado na Figura 3. Esse tipo é caracterizado por solos profundos de até 45 metros de profundidade e apresenta até sete horizontes, o que reduz o escoamento superficial, pois solos pouco profundos saturam-se rapidamente, contribuindo com o escoamento superficial. Essa característica corrobora a classificação de Sartoni et al. (2005) ao incluir esse tipo de solo no grupo hidrológico A, que compreende solos profundos, bem drenados, com alta taxa de infiltração e baixo escoamento superficial.
Na Tabela 3 observa-se os valores para cada parâmetro pedológico de entrada no SWAT de acordo com as classes determinadas de solo presentes da área de estudo.

Pelos dados dispostos na Tabela 3, verifica-se que a densidade aparente em latossolos na região de estudo é reduzida conforme há aumento da profundidade, indicando que essa classe de solo é mais compacta na superfície, ao passo que há um aumento da porosidade ao longo da profundidade. A porosidade, correspondente à relação de espaços vazios existente entre partículas com o volume total do solo, influi na dinâmica da água no solo (PRADO, 2013). Após a drenagem, a água fica armazenada nos microporos e o ar permanece nos macroporos.

Essa classe de solo consiste em textura argilosa, chegando a mais de $55 \%$ de argila no primeiro horizonte. Consequentemente, apresenta baixa permeabilidade, o que dificulta a infiltração e favorece o escoamento superficial.

Apesar de os latossolos dessa região serem profundos, as camadas superficiais apresentam baixo grau de porosidade devido ao elevado teor de argila. Isso acarreta dificuldade de infiltração da água para as camadas inferiores, facilitando a perda de solo e de nutrientes por causa do escoamento superficial.

A condutividade hidráulica do solo saturado apresentou valores maiores na superfície do solo do que nas camadas mais profundas, onde são encontrados teores superiores de argila e menor grau de porosidade.

Segundo Veihmeyer e Hendrickso (1949), a condutibilidade hidráulica do solo é diretamente proporcional à velocidade de infiltração. Trata-se da propriedade que expressa a facilidade com que a água se dispersa no perfil do solo, o que depende da quantidade, do tamanho, da morfologia, da continuidade e da orientação dos poros. Gonçalves e Libardi (2013) afirmam que a condutividade hidráulica na condição saturada depende mais da estrutura do que da textura do solo, e esse valor aumenta ao se elevar o grau de agregação de um solo. Comumente, valores superiores de condutividade hidráulica estão associados à maior porosidade. Entretanto, segundo Bouma (1982), pequenos poros contínuos podem conduzir mais água que poros maiores, pois estes apresentam descontinuidade no perfil do solo.

Com relação ao parâmetro HYDGRP que se refere ao grupo hidrológico do solo, indicando as características de infiltração. Mais de $75 \%$ da bacia apresenta solos do grupo A, que segundo a classificação de SCS (1972), representam solos bem drenados e profundos, compostos basicamente por areia e cascalhos, o que resulta em baixo escoamento superficial e alta infiltração.

Ressalta-se que a falta de dados nacionais/regionais de pedologia, isto é, quanto ao uso do solo e ao monitoramento hidrológico (qualidade e quantidade), ainda é uma questão a ser enfrentada. Além da problemática sinalizada, a aplicabilidade do SWAT também é dificultada por outras questões, tais como: inexistência/incerteza de dados nas demais variáveis de entrada, alta exigência computacional e temporal na obtenção de resultados e necessidade de calibração. Diante disso, sugere-se que esses pontos sejam alvos de futuros trabalhos visando ao desenvolvimento de estudos hidrológicos com o uso do modelo SWAT. 
Tabela 3. Parâmetros de cada classe de solo da bacia hidrográfica do rio Jucu, estado do Espírito Santo, Brasil

\begin{tabular}{|c|c|c|c|c|c|c|c|c|}
\hline Parâmetros & $\mathrm{LVd} 2$ & LVd3 & LVd12 & $\mathrm{Cd} 1$ & PV2 & AMd2 & Ad1 & $\mathrm{AR}$ \\
\hline NLAYERS & 7 & 7 & 5 & 5 & 5 & 3 & 6 & 2 \\
\hline HYDGRP & A & A & A & $\mathrm{C}$ & B & B & $\mathrm{C}$ & $\mathrm{D}$ \\
\hline SOL_Z1 & 120,00 & 200,00 & 200,00 & 100,00 & 100,00 & 100,00 & 80,00 & 150,00 \\
\hline SOL_BD1 & 1,32 & 1,14 & 1,90 & 1,08 & 1,70 & 1,80 & 1,70 & 1,70 \\
\hline SOL_AWC1 & 0,11 & 0,13 & 0,11 & 0,16 & 0,11 & 0,02 & 0,16 & 0,12 \\
\hline SOL_K1 & 5,00 & 18,00 & 18,00 & 12,50 & 12,50 & 500,00 & 20,00 & 20,00 \\
\hline CLAY1 & 44,65 & 39,00 & 37,62 & 33,00 & 17,08 & 1,00 & 22,00 & 17,86 \\
\hline SILT1 & 8,55 & 8,00 & 6,93 & 13,00 & 6,71 & 2,00 & 20,00 & 20,68 \\
\hline SAND1 & 41,80 & 53,00 & 54,45 & 54,00 & 37,21 & 97,00 & 58,00 & 55,46 \\
\hline ROCK1 & 5,00 & 0,00 & 1,00 & 0,00 & 39,00 & 0,00 & 0,00 & 6,00 \\
\hline SOL_Z2 & 300,00 & 400,00 & 400,00 & 270,00 & 280,00 & 270,00 & 300,00 & 700,00 \\
\hline SOL_BD2 & 1,32 & 1,14 & 1,46 & 1,10 & 1,50 & 1,80 & 1,70 & 1,70 \\
\hline SOL_AWC2 & 0,13 & 0,12 & 0,16 & 0,17 & 0,12 & 0,02 & 0,14 & 0,12 \\
\hline SOL_K2 & 4,40 & 10,00 & 4,40 & 5,00 & 5,00 & 500,00 & 12,50 & 20,00 \\
\hline CLAY2 & 52,25 & 43,70 & 55,44 & 44,00 & 25,62 & 1,00 & 26,00 & 21,36 \\
\hline SILT2 & 6,65 & 4,75 & 4,95 & 11,00 & 6,10 & 2,00 & 17,00 & 23,14 \\
\hline SAND2 & 36,10 & 46,55 & 38,61 & 45,00 & 29,28 & 97,00 & 57,00 & 44,50 \\
\hline ROCK2 & 5,00 & 5,00 & 1,00 & 0,00 & 39,00 & 0,00 & 0,00 & 11,00 \\
\hline SOL_Z3 & 700,00 & 900,00 & 1000,00 & 920,00 & 700,00 & 1600,00 & 450,00 & - \\
\hline SOL_BD3 & 1,09 & 0,98 & 1,48 & 1,16 & 1,20 & 1,80 & 1,70 & - \\
\hline SOL_AWC3 & 0,15 & 0,13 & 0,15 & 0,20 & 0,19 & 0,01 & 0,15 & - \\
\hline SOL_K3 & 3,80 & 5,00 & 4,40 & 3,80 & 2,50 & 500,00 & 12,50 & - \\
\hline CLAY3 & 57,04 & 52,47 & 56,43 & 48,00 & 60,75 & 1,00 & 32,00 & - \\
\hline SILT3 & 5,52 & 3,96 & 6,93 & 10,56 & 2,43 & 5,00 & 17,00 & - \\
\hline SAND3 & 29,44 & 42,57 & 35,64 & 37,44 & 17,82 & 96,00 & 51,00 & - \\
\hline ROCK3 & 8,00 & 1,00 & 1,00 & 4,00 & 19,00 & 0,00 & 0,00 & - \\
\hline SOL_Z4 & 1900,00 & 2000,00 & 1600,00 & 1270,00 & 1200,00 & - & 700,00 & - \\
\hline SOL_BD4 & 1,09 & 1,03 & 1,46 & 1,36 & 1,20 & - & 1,60 & - \\
\hline SOL_AWC4 & 0,16 & 0,12 & 0,15 & 0,20 & 0,20 & - & 0,17 & - \\
\hline SOL_K4 & 3,80 & 5,00 & 4,40 & 3,80 & 2,50 & - & 5,00 & - \\
\hline CLAY4 & 57,66 & 51,41 & 55,44 & 44,10 & 63,08 & - & 37,00 & - \\
\hline SILT4 & 5,58 & 4,85 & 4,95 & 14,70 & 3,32 & - & 23,00 & - \\
\hline SAND4 & 29,76 & 40,74 & 38,61 & 39,20 & 16,60 & - & 40,00 & - \\
\hline ROCK4 & 7,00 & 3,00 & 1,00 & 2,00 & 17,00 & - & 0,00 & - \\
\hline SOL_Z5 & 3200,00 & 3200,00 & 1960,00 & 1620,00 & 1700,00 & - & 1150,00 & - \\
\hline SOL_BD5 & 1,09 & 1,15 & 1,40 & 1,42 & 1,20 & - & 1,70 & - \\
\hline SOL_AWC5 & 0,17 & 0,14 & 0,15 & 0,19 & 0,19 & - & 0,21 & - \\
\hline SOL_K5 & 3,80 & 4,40 & 4,40 & 20,00 & 2,50 & - & 12,50 & - \\
\hline CLAY5 & 57,96 & 55,29 & 55,44 & 23,76 & 51,80 & - & 33,00 & - \\
\hline SILT5 & 5,52 & 3,88 & 4,95 & 34,65 & 5,18 & - & 35,00 & - \\
\hline SAND5 & 28,52 & 37,83 & 38,61 & 40,59 & 17,02 & - & 32,00 & - \\
\hline ROCK5 & 8,00 & 3,00 & 1,00 & 1,00 & 26,00 & - & 0,00 & - \\
\hline SOL_Z6 & 4500,00 & 3900,00 & - & - & - & - & 1300,00 & - \\
\hline SOL_BD6 & 1,09 & 1,15 & - & - & - & - & 1,80 & - \\
\hline SOL_AWC6 & 0,15 & 0,14 & - & - & - & - & 0,01 & - \\
\hline SOL_K6 & 3,80 & 5,00 & - & - & - & - & 500,00 & - \\
\hline CLAY6 & 54,60 & 43,70 & - & - & - & - & 0,96 & - \\
\hline SILT6 & 4,55 & 7,60 & - & - & - & - & 4,80 & - \\
\hline SAND6 & 31,85 & 43,70 & - & - & - & - & 90,24 & - \\
\hline ROCK6 & 9,00 & 5,00 & - & - & - & - & 4,00 & - \\
\hline SOL_Z7 & 5700,00 & 4500,00 & - & - & - & - & - & - \\
\hline SOL_BD7 & 1,09 & 1,60 & - & - & - & - & - & - \\
\hline SOL_AWC7 & 0,16 & 0,09 & - & - & - & - & - & - \\
\hline SOL_K7 & 3,80 & 60,00 & - & - & - & - & - & - \\
\hline CLAY7 & 53,94 & 18,62 & - & - & - & - & - & - \\
\hline SILT7 & 4,65 & 16,66 & - & - & - & - & - & - \\
\hline SAND7 & 34,41 & 62,72 & - & - & - & - & - & - \\
\hline ROCK7 & 7,00 & 2,00 & - & - & - & - & - & - \\
\hline
\end{tabular}

Fonte: Elaborada pelo autor (2018)

LVd2: Latossolo vermelho amarelo distrófico A moderado, textura argilosa fase floresta subperenifólia, relevo forte ondulado; LVd3: Latossolo vermelho amarelo distrófico A moderado, textura argilosa fase floresta subperenifólia, relevo montanhoso e forte ondulado; LVd12: Latossolo vermelho amarelo distrófico A moderado, textura argilosa fase floresta subperenifólia, relevo suave ondulado; Cd1: Cambissolo háplico distrófico A moderado, textura argilosa e média fase floresta perenifólia, relevo montanhoso e forte ondulado; PV2: Argissolo vermelho amarelo álico A moderado, textura argilosa fase floresta subcaducifólia, relevo ondulado; AMd2: Neossolo quartzarênico distrófico A moderado, fase arenosa floresta subperenifólia de restinga, relevo plano; Ad1: Neossolo flúvico distrófico A fraco e moderado, textura média fase floresta perenifólia de vársea, relevo plano; AR: Neossolo litólico eutrófico A moderado, textura média e argilosa floresta subperenifólia e subcaducidólia, relevo escarpado, montanhoso e forte ondulado. 
Por sua vez, os procedimentos aplicados neste trabalho foram capazes de gerar resultados compatíveis com a região de estudo, localizada no sul do estado do Espírito Santo. Espera-se que eles sirvam como subsídio para trabalhos futuros na mesma região ou como guia a outros em regiões diferentes, os quais poderão seguir a metodologia apresentada para obtenção dos valores dos parâmetros pedológicos exigidos pelo SWAT na estimativa de vazões.

\section{CONCLUSÕES}

Os parâmetros pedológicos usados na bacia hidrográfica do rio Jucu tem utilidade em simulações hidrológicas com o uso do modelo SWAT da mesma região ou em outras localidades evitando uso de valores de parâmetros pedológicos pouco condizentes com a realidade local.

\section{REFERÊNCIAS}

AKSOY, E.; OZSOY, G.; DIRIM M. S. Soil mapping approach in GIS using Landsat Satellite Imagery and DEM data. African Journal of Agricultural Research, v. 4, n. 11, p. 1295-1302, 2009

ABBASPOUR, K. C.; ROUHOLAHNEJAD, E.; VAGHEFI, SRINIVASANB， S. R.; YANG, H.; KLØVE, B.. A continental-scale hydrology and water quality model for Europe: Calibration and uncertainty of a high-resolution large-scale SWAT model. Journal of Hydrology, v. 524, p.733-752, 2015. 10.1016/j.jhydrol.2015.03.027.

ARNOLD, J. G.; MORIASI, D. N., GASSMAN, P. W.; ABBASPOUR, K. C.; WHITE, J. M.; SRINIVASAN, R.; SANTHI, C.; HARMEL, R. D.; VAN GRIESVEN, A.; VAN LIEW, M. W.; KANNAN, N., KA, M., K. SWAT: Model use, Calibration and validation. Transactions of the ASABE, v. 55, n. 4, p. 1491-1508, 2012. 10.13031/2013.42249.

ARNOLD, J. G.; SRINIVASAN, R.; MUTTIAH, R. S.; WILLIAMS, J. R. Large area hydrologic modeling and assessment - Part I: Model development. Journal of American Water Resource Association, v.34, n.1, p. 73-89, 1998. 10.1111/j.1752-1688.1998.tb05961.x

BOUMA, J. Measuring the conductivity of soil horizons with continuous macropores. Soil science society of America, v. 46, $\quad$ p. $\quad 438-\quad 441, \quad 1982$. 10.2136/sssaj1982.03615995004600020047x

BRESSIANI, D. A.; GASSMAN P. W.; FERNANDES J. G.; GARBOSSA L. H. P.; SRINIVASAN R.; BONUMÁ N. B.; MENDIONDO, E. M. Review of Soil and Water Assessment Tool (SWAT) applications in Brazil: Challenges and prospects. International Journal of Agriculture \& Biology $\begin{array}{lllll}\text { Engineering, } & \text { v.8, } & \text { n.3, p. } & \text { 9-35, } 2015 .\end{array}$ 10.3965/j.ijabe.20150803.1765

BROUZIYNE, Y.; ABOUABDILLAH, A.; BOUABID, R.; BENAABIDATE, L.; OUESLATI, O. SWAT manual calibration and parameters sensitivity analysis in a semi-arid watershed in North-western Morocco. Arabian Journal Of Geosciences, v. 10, n. 19, p.1-13, 2017. 10.1007/s12517017-3220-9
BUOL, S. W. Soils and agriculture in Central-West and North Brazil. Scientia Agricola, v. 66, n.5, p. 697-707, 2009. 10.1590/S0103-90162009000500016

COSGROVE, W. J.; LOUCKS, D. P. Water management: Current and future challenges and research directions. Water Resources Research, v. 51, n. 6, p.4823-4839, 2015. 10.1002/2014WR016869

DENT, D.; YONG, A. Soil survey and land evaluation. London, G. Allen e Unwin, 1981. 278 p.

DI LUZIO, M.; NORFLEET, M. L.; ARNOLD, J. G.; WILLIAMS, J. R.; KINIRY, J. R. A. A soil parameters geodatabase for the modeling assessment of agricultural conservation practices effects in the United States. International Journal of Geospatial and Environmental Research, v.1, n.2, Artigo 6, 2015.

DIAS JUNIOR, M. S.; BERTONI, J. C.; BASTOS, A. R. R. Curso de pós-graduação em solos e nutrição de plantas. Universidade Federal de Lavras, Departamento de Ciências do Solo - Setor de Física do Solo, Lavras, 2000.

EMAM, A. R.; KAPPAS, M.; NGUYEN, L. H. K.; RENCHIN, T. Hydrological Modeling in an Ungauged Basin of Central Vietnam Using SWAT Model. Hydrology And Earth System Sciences Discussions, p.1-33, 2016. 10.5194/hess-2016-44.

EMBRAPA. Empresa Brasileira de Pesquisa Agropecuária. Levantamento de reconhecimento dos solos do estado do Espírito Santo. 1978. Disponível em: <https://www.embrapa.br/busca-de-publicacoes//publicacao/335800/levantamento-de-reconhecimento-dossolos-do-estado-do-espirito-santo>. Acesso em: 8 ago. 2016.

FRANCESCONI, W.; SRINIVASAN, R.; PÉREZ-MIÑANA, E.; WILlCOCKD, S. P.; QUINTERO, M.. Using the Soil and Water Assessment Tool (SWAT) to model ecosystem services: A systematic review. Journal of Hydrology, v. 535, p.625-636, 2016. 10.1016/j.jhydrol.2016.01.034.

FUKUNAGA, D. C.; CECÍLIO, R. A.; ZANETTI, S. S.; OLIVEIRA, L. T.; CAIADO, M. A. C. Application of the SWAT hydrologic model to a tropical watershed at Brazil. $\begin{array}{llll}\text { Catena } & \text { v. } & 125, & \text { p.206-213, }\end{array}$ 10.1016/j.catena.2014.10.032.

GONÇALVES, A. D. M. de A.; LIBARDI, P. L. Análise da determinação da condutividade hidráulica do solo pelo método do perfil instantâneo. Revista Brasileira de Ciência do Solo, v. 37, p. 1174-1184, 2013. 10.1590/S010006832013000500007.

GYAMFI, C.; NDAMBUKI, J. M.; SALIM, R. W.. Application of SWAT Model to the Olifants Basin: Calibration, Validation and Uncertainty Analysis. Journal of Water Resource And Protection v. 08, n. 03, p.397-410, 2016. 10.4236/jwarp.2016.83033. 
KOUCHI, D. H.; ESMAILI, K.; FARIDHOSSEINI, A.; SANAEINEJAD, S. H.; KHALILI, D.; ABBASPOUR, K. C. Sensitivity of calibrated parameters and water resource estimates on different objective functions and optimization algorithms. Water, v. 9, n. 6, p.384-400, 2017. 10.3390/w9060384.

LEPSCH, I. F. Status of soil surveys and demand for soil series descriptions in Brazil. Soil Horizons, v.54, n.2, p. 1-5, 2013. 10.2136/sh2013-54-2-gc.

LEYTON, J. M. O. Assessment of SWAT to enable development of watershed management plans for agricultural dominated systems under data poor conditions. Virginia, 2012. 160f. Tese (Doutorado em Biological Systems Engineering) - Virginia Polytechnic Institute and State University, Blacksburg, 2012.

MALAGÓ, A.; BOURAOUI, F.; VIGIAK, O.; GRIZZETTI, B.; PASTORI, M. Modelling water and nutrient fluxes in the Danube River Basin with SWAT. Science of the Total Environment, v. 603-604, p.196-218, 2017. 10.1016/j.scitotenv.2017.05.242.

MOREIRA, L. L.; SCHWAMBACK, D.; RIGO, D. Sensitivity analysis of the Soil and Water Assessment Tools (SWAT) model in streamflow modeling in a rural river basin. v. 13, n. 6, e2221, 2018. 10.4136/ambi-agua.2221

NEITSCH, S. L.; ARNOLD, J. G.; WILLIAMS, J. R. Soil and water assessment tool - Theoretical Documentation: Version 2009. Temple: Blackland Research Center, Texas AgriLife Research, 2011. 647p.

OCHOA, V.; URBINA-CARDONA, N.. Tools for spatially modeling ecosystem services: Publication trends, conceptual reflections and future challenges. Ecosystem Services, v. 26, p.155-169, 2017. 10.1016/j.ecoser.2017.06.011.

PRADO, H. do. Pedologia fácil. Piracicaba: Hélio do Prado, 2013.
REICHARDT, K.; TIMM, L. C. Solo, planta e atmosfera: conceitos, processos e aplicações. Barueri, SP: Manole, 2004.

SARTONI, A.; LOMBARDI NETO, F.; GENOVEZ, A. M. Interceptação. Classificação Hidrológica de Solos Brasileiros para a Estimativa da Chuva Excedente com o Método do Serviço de Conservação do Solo dos Estados Unidos Parte 1: Classificação. Revista Brasileira de Recursos Hídricos, v.10, n. 4, p. 5-18, 2005. 10.21168/rbrh.v10n4.p5-18.

SIMONOVIC, S. P. World water dynamics: global modeling of water resources. Journal of Environmental Management, v.66, n.3, p. 249-267, 2002. 10.1006/jema.2002.0585.

SOIL CONSERVATION SERVICE (SCS). National Engineering Handbook, Section 4: Hydrology. Washington DC: Department of Agriculture, 1972. 762p.

SOIL CONSERVATION SERVICE (SCS). Soil mechanics level I. Module 3 - USDA Textural Soil Classification. U.S. Department of Agriculture, Washington, DC, 1987.

SOIL CONSERVATION SERVICE ENGINEERING DIVISION (SCS). Urban hydrology for small watersheds. U.S. Department of Agriculture, Washington, DC: Technical Release 55, 1986.

STEHR, A.; DEBELS, P.; ROMERO, F.; ALCAYAGA, H. Hydrological modelling with SWAT under limited conditions of data availability: evaluation of results from a Chilean case study. Hydrological Sciences Journal, v.53, n.3, p. 588-601, 2008. 10.1623/hysj.53.3.588.

TARAWNEH, E.; BRIDGE, J.; MACDONALD, N. A precalibration approach to select optimum inputs for hydrological models in data-scarce regions. Hydrology and Earth System Sciences, v. 20, n. 10, p.4391-4407, 2016. 10.5194/hess-20-4391-2016.

VEIMEHYER, F. J.; HENDRICKSON, A. H. Methods of measuring field capacity and permanent wilting percentage of soils. Soil Science, v. 68, p. 75-94, 1949. 